\title{
Teaching Academic Vocabulary to English Language Learners (ELLs)
}

\author{
Liping Wei \\ College of Education and Health Professions, University of Houston-Victoria, TX, USA
}

\begin{abstract}
Confronted with dual learning tasks-learning English as a $2^{\text {nd }}$ language and grade-level content, English Language Learners (ELLs) in K-12 are often found struggling to become fluent in English and falling behind in academic studies. It is commonly recognized that academic vocabulary is strongly related to academic achievement. Academic vocabulary is of critical importance in content learning and key to classroom interactions as students are engaged in learning activities using academic language. This article will zero in on the challenges students encounter in learning academic vocabulary. It will start with the importance of teaching ELLs academic vocabulary, followed by a classification of academic vocabulary, and an elaboration of the characteristics of academic language. Teacher candidates will explore why sheltered instruction is indispensable for the learning of vocabulary and how the two main sources of word learning-incidental learning and explicit instruction, facilitates vocabulary development. The focus will be placed on the specific strategies to help students develop a rich academic vocabulary inventory. It is hoped that teacher candidates will walk away with some guiding principles on teaching academic vocabulary and find these principles helpful in their classrooms with ELLs.
\end{abstract}

Index Terms —English language learners, academic vocabulary, strategies, principles

\section{INTRODUCTION}

As the fastest growing demographic in U.S. public schools over the past decades, English Language Learners (ELLs) are the student population no educators can ignore. In the 2012-2013 school year, ELL students accounted for 9.2\% (an estimated 4.4 million) of the total student population nationally (Kena et al., 2015), whereas in the school year 2018 the U.S. Department of Education reported an estimated 5.0 million ELLs enrolled in public schools representing approximately 10.2 percent of the public school enrollment (Irwin et al., 2021). Among the 50 states, Texas has 18.7 percent of ELLs in its public schools, only next to California (19.4 percent) (Irwin et al., 2021). According to Migration Policy Institute, foreign-born immigrants made up 17.0 percent of the Texas population in 2016, compared to 13.5 percent across the United States (Sugarmann \& Geary, 2018). By 2025, minorities are expected to account for 50\% or more of the population of Texas.

These ELLs are in the process of developing their English language proficiency and in the meantime learning academic content across subject areas. The current education policies require that all ELLs must take English proficiency tests every year until they are "re-designated" as fluent English proficiency speakers. Additionally, they are held to the same language arts, math, science, and other content-area standards, and required to take and pass the same standards-based tests as their native-English-speaking peers.

Therefore, compared to the native-English-speaking students, ELLs are confronted with dual learning tasks: learning English as a $2^{\text {nd }}$ language and grade-level content in the language they have not been fully proficient in. Both of the tasks can be daunting and ELLs are often found struggling to become fluent in English and falling behind in academic achievement tests. It is reported that ELL students showed reading proficiency levels that were $23 \%$ to $30 \%$ lower than native-English-speaking students (Kena et al., 2015). Science scores of ethnic minority groups (except Asian Americans) continue to compare unfavorably with their Euro-American counterparts (as cited in Ovando \& Combs, 2012). Poor academic performance often associates with the issues of student retention. The ELL students' school dropout rates are almost double that of their native-English-speaking peers (Espinosa, 2008).

The challenges faced by ELL students may come from many aspects, linguistically, academically, emotionally, and socioculturally, and all these challenges greatly influence their education success. This article will zero in on the challenges students encounter in learning academic vocabulary. It will start with the importance of teaching academic vocabulary to ELLs, followed by a classification of academic vocabulary, and an elaboration of the characteristics of academic language. The focus will be placed on the general principles of teaching academic vocabulary and specific vocabulary development strategies.

\section{The IMPORTANCE OF TEACHING ACADEMIC VOCABULARY TO ELLS}

Academic vocabulary is of critical importance in content learning. Students need to discuss, read, and write about the academic content using academic vocabulary, e.g., the names of important people, places, and events, scientific and mathematical terms, and concepts. Academic vocabulary is also key to classroom interactions as students are engaged 
in various learning activities using the language. Students' vocabulary development is strongly related to academic achievement. Students with robust vocabularies are more likely to be successful in school. To be academically successful, it is important that students acquire grade-appropriate general academic and domain-specific vocabulary. We cannot overestimate the importance of teaching academic vocabulary. Even for the subject matters like math whose concepts people commonly think translate across languages, students will well struggle with it, if without mastery of the related vocabulary.

Additionally, if you identify with the Lexical Approach, an approach of teaching foreign languages proposed by Michael Lewis in the early 1990s (Lewis, 1993), you must concur on how important vocabulary is for communication. The Lexical Approach rests on the notion that an important part of learning a language consists of being able to understand and produce lexical phrases as chunks. Chunks include collocations, fixed and semi-fixed expressions, and idioms. Fluency does not depend on a set of generative grammar rules or a separate store of isolated words. Instead, it depends on the ability to rapidly access this inventory of chunks. These chunks occupy a crucial role in facilitating language production and are the key to fluency. Native speakers have a large inventory of lexical chunks that are vital for fluent production.

Therefore, according to the Lexical Approach, lexis is central in creating meaning, whereas grammar plays a subservient managerial role. Grammatical mastery is not a requirement for effective communication. The building block of language learning is lexis, not grammar. If you accept this principle, then the logical implication is that we should spend more time helping learners develop their stock of phrases and less time on grammatical structures. Any meaningcentered syllabus should be organized around lexis rather than grammar, and aim to raise learners' awareness of the lexical nature of the language.

\section{CATEGORIES OF ACADEMiC VocABUlary}

There are varied types of academic vocabulary. Typically, we can classify them into three categories.

$\checkmark$ General academic vocabulary

This type of vocabulary is used in all academic disciplines and includes some high-frequency words used in academic and social conversations.

Examples include and are not limited to "describe," "predict," "argue," "analyze," "utilize," "summarize," "sequence," “compare," “infer," "measure," “chart," "model," “structure," “symbol," “effect," "evidence," "circumstances," "source," "modify," "classify," "list," "debate," "explain," etc.

$\checkmark$ Content vocabulary

This type of vocabulary is subject-specific and associated with a particular topic being taught. It is not very frequently used outside of the classroom. They are often the words highlighted in the textbooks that students need to understand the content.

Examples include and are not limited to: "numerator" and "denominator" in math; "transpiration" in science; "communism," "socialism," and "capitalism" in social science, etc.

$\checkmark$ Word parts: roots and affixes

Learning word parts enables students to defer the meaning of new vocabulary. It also helps students to see that words related by structure are usually also related by meaning.

Examples include and are not limited to:

"Photo"-(light): "photosynthesis," "photocopy," "photograph," "photography"

"Vis"-(to see): "vision," "visual," "visualize," "visible"

For instance, when a science teacher teaches photosynthesis, he/she can help students learn the meaning of photosynthesis by introducing the meaning of the root, "photo" (light). Once students know that "vis" is the root meaning "to see," they can begin to guess the meaning of words like "visualize" and "visible." Students can therefore see how these words are related by prefix, root, and suffix.

Another category that carries implications to educators is the three tiers of vocabulary development posited by Beck, McKeown, and Kucan (2013).

$\checkmark$ Tier 1 words

They are high-frequency words that are most commonly found in written materials, such as simple nouns, verbs, and sight words. Examples are "book," "girl," "sad," "run," "dog," and "orange," etc. These words typically do not have multiple meanings. Most students know these words conversationally, and usually it is not necessary to focus on them instructionally.

$\checkmark$ Tier 2 words

These are the words important for reading comprehension and academic success. They are across the curriculum and are more likely to appear in written texts than in speech. They are usually high-frequency vocabulary items, which is also characteristic of mature language users. Tier 2 words are academic vocabulary that should be taught explicitly. Examples include "vary," "formulate," "specify," "itemize," "periphery," "dignified," "unabashedly," etc. Teachers are recommended to focus on Tier 2 words in their vocabulary lessons. A caveat is that for newcomers and emergent speakers, they may need to start with the explicit instruction and practice with Tier 1 words. 


\section{Tier 3 words}

They are low-frequency and domain-specific vocabulary. Often unique to a particular topic, they are key to understanding new concepts in content areas. These words are typically uncommon, and students learn these words when a specific need arises, such as learning "amino acid" during a chemistry lesson. Tier 3 and Tier 2 words are not clear-cut in some cases, and both should be integrated into the teaching of content.

\section{Characteristics of Academic Language}

Before investigating how to help students develop academic vocabulary, it is essential to illuminate the characteristics of academic language. Different from day-to-day conversational language, academic language contains some special linguistic features at the word, phrase, and discourse levels.

$\checkmark$ Using common words that take on a new meaning in a particular context

The words with multiple meanings often look simple. However, if not explicitly taught, they are the ones that frequently trick ELLs and struggling readers. For example,

"Rational" and "irrational" when referring to numbers instead of mental states

"Table" and "chair" vs. data "table"

- "Legislative power" vs. "electrical power"

$\checkmark$ Using connectors that show relationships, logic, and sequence

We can understand them as transition words and logical connectors. For example,

- "therefore," "although," "because," "however," "similarly," "in contrast," "first," "second," "finally," and "next"

$\checkmark$ Using qualifiers that soften a claim or leave room for exceptions

For example,

D "generally," "theoretically," "seldom," "often," "may," and "might"

$\checkmark$ Using particular grammatical structures

For example, passive voice is often used to make the message impersonal. Teachers should be aware of the syntax used in their subject areas and bring it to students' attention to facilitate their learning of both content and language.

$\checkmark$ Using dependent clauses

A series of dependent clauses may be used, therefore creating long and complex sentences and abstract relationships within and across the clauses. ELLs need the ability to decipher the meaning of each clause to grasp the overall meaning.

$\checkmark$ Using a variety of discourse structures

ELLs will benefit from understanding different types of writing, such as (a) narrative structures found in telling stories; (b) expository structures that serve to explain, compare and contrast, show cause and effect, or delineate a procedure; (c) persuasive structures that aim to influence audience; and (d) descriptive structures that intend to describe something. Explicit instruction on discourse structures can help students comprehend and produce the texts more effectively.

\section{SHELTERED INSTRUCTION-INTEGRATING LANGUAGE AND CONTENT}

Next, let's look at how we can more effectively teach academic vocabulary to ELLs. We'll start with "Sheltered Instruction," an approach to teaching ELLs that integrates both language and content instruction. In "Sheltered Instruction," as the name suggests, ELL students are "sheltered" in the sense that they are protected from the language demands of mainstream instruction that is very likely beyond their comprehension. Basically, it is grade-level content instruction used to make academic content understandable to ELLs while promoting their English language development.

With the high-stakes assessment policies, teachers cannot wait till ELLs acquire enough English to start teaching them academic content, neither can they water down the curriculum to compromise students' levels of English proficiency. Instead, they must provide the grade-level curriculum to ELLs in a manner comprehensible to them. Therefore, language and content must be integrated into the teaching of ELLs, and sheltered instruction, to a large degree, is indispensable in the current educational backdrop. We must realize that sheltered instruction offers an effective framework in guiding ELLs to develop their language proficiency, including academic vocabulary. In traditional foreign language teaching, vocabulary items are usually taught in an isolated way. Many teacher candidates perhaps still remember copying the vocabularies from the board and writing them over and over again to commit them to the memory when learning a foreign language in high school. How effective this method is in teaching vocabulary is highly questionable. Ideally, vocabulary should be presented in context, not in isolation. Isolated vocabulary instruction does not promote vocabulary and language development to the greatest possible extent.

Language instruction is best delivered through context-embedded experience. In other words, content-based instruction provides an authentic and meaningful situation that allows language learning to take place through 
interactions and contextualized communication. When language learning is embedded in content instruction, the rich, natural language that is part and parcel of academic instruction best facilitates vocabulary development.

\section{INCIDENTAL LEARNING \& EXPLICIT INSTRUCTION}

Peregoy and Boyle (2017) summarized two main sources of word learning-incidental learning and explicit instruction. Incidental learning refers to learning through exposure to the target language and using the language in communicative contexts. Examples include learning through social interactions, academic instruction, independent reading, guided reading, etc. Explicit instruction involves explicitly teaching the new words (high-frequency words, content-area terms, low-frequency words as needed, etc.) as well as strategies to understand, remember, and use new words (word analysis, using prefixes/suffixes/roots, using dictionaries, etc.) (See Peregoy \& Boyle, 2017, p. 260).

\section{A. Incidental Learning}

Teachers need to know that just as first language acquisition, most second language vocabulary development is more likely to be implicit or incidental. The "incidental learning" coincides with the Innatist perspective of Second Language Acquisition (SLA) Theory spearheaded by Chomsky (1957, 1965) and Krashen (1985, 2004a). Compared with the Behaviorist perspective believing that children learn a language through repetition, imitation, and reinforcement and the Interactionist perspective believing that a second language is learned through communication and interaction, the Innatist theory believes that human being is born with a natural ability or innate capability to learn a language.

According to Chomsky, children are born with Language Acquisition Device (LAD) - a mental mechanism that enables children to figure out the underlying rules of the language on their own, based on the exposure to the language. The underlying rules are referred to as Universal Grammar. It argues that a great many of the abstract language rules are common to all languages, rather than language-specific. They are genetically programmed into all human children. Once the LAD is activated and children internalize the rules of the language, they can generate an infinite number of unique and grammatically correct utterances. Of course, they will run into trouble when the language used does not fit their hypotheses. However, with time and scaffolding, they will get to figure out some exceptions to particular hypotheses and start modifying their own hypotheses accordingly. Therefore, the implications of the Innatist perspective for teachers are: Children build grammar through a process of hypothesis development and testing; teachers should provide students with abundant language samples and opportunities for this process to happen.

Stephen Krashen's monitor theory is heavily influenced by Chomsky's Innatist perspective. Krashen's monitor model consists of five interrelated hypotheses (1985, 2004a):

$\checkmark$ The Acquisition vs. Learning Hypothesis

Language acquisition is a subconscious process while language learning is a conscious process. Language learning happens primarily in the classroom, whereas language acquisition happens in natural settings. The acquisition allows us to use the language while learning allows us to talk about the language. Krashen argues that the majority of language development comes from acquisition rather than learning.

$\checkmark$ The Natural Order Hypothesis

Language is acquired in a natural order. Though the exact order in which a target language is acquired is not completely known, it reminds teachers that "drilling a student on a grammatical item before he or she is ready to acquire it will be of little use" (Wright, 2015, p. 51).

$\checkmark$ The Monitor Hypothesis

"Monitor" is like leverage that regulates the accuracy of language use. When our focus is on expressing meaning without attention to language forms, we may sacrifice accuracy for fluency. These are the times when the monitor is underused. When we place too much emphasis on language accuracy, the complexity and subtlety of the meaning we can express will be compromised. These are the times when the monitor is overused. A language learner should constantly be self-conscious of his/her language use to assure that he/she is producing conventional and understandable language. At the same time, he/she cannot be too self-conscious, which may prevent him/her from expressing ideas freely. A conundrum for ELL teachers is how to help language learners become optimal monitor users.

$\checkmark$ The Input Hypothesis

This hypothesis is the key to Krashen's monitor model. Krashen uses some formulae to explain what comprehensible input means. When the input is i+0 which means the input contains no linguistic knowledge beyond the learner's current competence, no acquisition takes place. When the input is $\mathrm{i}+10$ which means the input is too far beyond the learner's current competence, no acquisition takes place either because the input "becomes incomprehensible noise" (Freeman \& Freeman, 2011, p. 121). Only when the learner receives comprehensible input that contains the language slightly beyond his/her current level of competence (i+1) can acquisition happen. Krashen asserts that comprehensible input is the source of all acquired language.

$\checkmark$ The Affective Filter Hypothesis

This hypothesis is concerned with the affective factors in language acquisition, such as boredom, anxiety, lack of interest, or motivation. It maintains that when affective filter is too high, it blocks comprehensible input so 
language acquisition cannot happen. This hypothesis explains why learning outcomes may vary among students even when the amount of comprehensible input they receive is the same.

Krashen summarizes the five hypotheses in this fashion, "People acquire second languages only if they obtain comprehensible input and if their affective filters are low enough to allow the input in" (1985, p. 4). You may see that this model has some overlaps with the Interactionist perspective in that language is learned from the environment around them through communication and interaction rather than imitation and memorization. This theory is helpful in informing teachers about the importance of creating a positive, language-rich learning environment where ELL students can grow to be the agents of their own language development.

Besides the monitor model, Krashen (2004b) put forward another concept that has provided valuable insight, that is, "free voluntary reading" or "recreational reading." "Reading comprehension supports vocabulary development" and "vocabulary development supports reading comprehension" (Lawrence, White, \& Snow, 2011, p. 2). "Reading is one of the primary means by which ELLs acquire new vocabulary words" (Wright, 2015, p. 192). Wright (2015) reasoned that students need to know thousands of words to comprehend authentic and complex texts, and it is impossible to provide direct vocabulary instruction for all unknown words. Fortunately, ELLs can naturally acquire the vast majority of vocabulary simply by engaging in extensive reading of all genres. However, teachers should remember that for vocabulary development to happen, it is important ELLs read materials geared to their English proficiency level and reading ability in particular.

Through examining Chomsky and Krashen's first and second language acquisition theories, it is hoped that teacher candidates can become more cognizant of the importance of incidental learning in helping ELLs to develop vocabulary. Moreover, having read about Chomsky's LAD and Universal Grammar and Krashen's monitor model, teacher candidates will benefit from reflecting on what it means to their classroom teaching. In a nutshell, teachers will find themselves doubling the results with half of the efforts when creating opportunities for incidental learning to happen.

\section{B. Explicit Instruction}

Apart from incidental learning, explicit instruction plays a very important role in students' vocabulary development. Paton and Wilkins (2009) claim that through explicit instruction teachers can help learners with the move from unconscious to conscious processing of the language by providing regular teaching of relevant items of phonology, morphology, syntax, and semantics. The classroom is an ideal place that provides teaching and repetition in the way that real life outside of the classroom cannot. Teachers can select the linguistic items with an eye on their usefulness and frequency in learners' real life. Furthermore, the linguistic items taught in the classroom should be contextualized in ways that reflect how they may be actually used by learners in the real world.

Systematic vocabulary instruction is also critical for ELLs' learning of academic content. A widely agreed-upon difficulty ELLs frequently face in learning academic vocabulary stems from the nature of the language related to specific subject areas. For example, science has a considerable number of terms characterized by everyday-life vocabulary but with different meanings in the science context, which therefore constitutes a big barrier for ELLs in mastering science concepts.

Explicit instruction entails (a) providing direct instruction on the words teachers deem most important for understanding the material under study; (b) teaching word-learning strategies, including word parts, prefixes, suffixes, and roots, (c) helping students to figure out the meaning of the new words they come across and choose the most appropriate words to convey messages in communication, and (d) fostering word consciousness among students. Additionally, teachers need to understand that students know a word at different levels. When a student knows a word by simply recognizing the word and understanding its meanings in different contexts, the student knows the word receptively. When a student knows a word by being able to produce sentences using the word appropriately, the student knows the word productively. For students to know words productively, in explicit instruction, teachers need to employ multiple interactive strategies that allow students to acquire vocabulary through communication in different contexts, and students need to actively engage in the learning activities instead of being passive receivers only. A common pitfall of explicit instruction is the overreliance on rote learning that may result in students' inability to use the vocabulary for authentic purposes. Rote learning is a necessary part of explicit instruction. However, rote learning alone does not lead to language development, especially communicative competence, nor is it an effective way of vocabulary teaching. Well-designed and student-centered activities should always be the key to explicit instruction.

\section{VocABUlaRy DEVELOPMENT STRATEGIES IN CONTENT INSTRUCTION}

This section will explore in-depth the specific strategies on how to help students develop a rich vocabulary inventory.

$\checkmark$ Reviewing concepts

Teachers should help students to review important concepts whenever necessary rather than automatically assuming that students know these concepts. In reviewing concepts, teach the important terms that may be abstract or confusing to students but the key to their understanding of the content. For instance, the lesson on multiplication of two-digit numbers may require an explanation/ review/teaching of pertinent vocabularies, such as "product," "sum," "carry," "exchange," and "equal."

$\checkmark$ Building vocabulary 
Before teaching a new topic or content, examine the material to identify the vocabulary that will be new to students or that may create problems hence needing explanations. Teach these vocabulary words and their synonyms and antonyms to assist students in understanding. For the words with multiple meanings, help students develop the nuances of meaning in particular content, and understand how a word is used in different contexts to carry different connotations and what may be appropriate in one context may not be appropriate in another.

$\checkmark$ Modeling the correct use of the academic terms

It is important for teachers to use academic terms appropriately with students whenever they are able, so students can receive as much input as possible for language acquisition to happen. Physical movement is often vital to getting meanings across to students. For instance, when teaching "subtraction," teachers can act out "taking away" to help students understand the "difference" by discussing an example of subtraction. Having students involved and interact with each other will also be helpful for students to understand the process required for doing subtraction.

$\checkmark$ Using the vocabulary commensurate with students' English proficiency levels

ELLs may come with varying English proficiency levels. Accommodations and modifications must be provided in every content area for ELLs to develop language proficiency and learn academic content. One thing teachers need to know is that students may not read at the same level as the instructional materials being utilized. Teachers should always be sensitive about and aware of students' proficiency levels. For the text to be at students' instructional level or slightly above, and also for providing ELLs with access to increasingly challenging texts, teachers sometimes have to rewrite the text by simplifying the sentence structures to reduce the complexity and/or explaining the content in terms students can more easily understand. An abridged version of the text is an option, too. Teachers can also use read-aloud to read each sentence carefully, one at a time, to decipher the meaning and the key elements from the sentence in a dense text.

Additionally, teachers should carefully monitor the vocabulary and sentence structures they use with ELLs in their instruction so that their language can be aligned with students' proficiency levels. Avoid using complex sentences or idioms students may not understand, particularly with students at the beginning proficiency level. When giving complex instructions, use simple English, give short and concise directions one step at a time, and repeat them as often as needed. When teaching abstract content, use language that is straightforward, clear, and accompanied by a visual representation. Speak slowly and clearly so students can follow along.

$\checkmark$ Building on students' background knowledge

Background knowledge plays a significant role in students' learning of academic vocabulary. Learning becomes easier when it is built on students' background knowledge. As background knowledge grows, students develop in their abilities to acquire academic vocabulary and understand complex subject matters. Effective use of academic vocabulary requires a growing reservoir of background knowledge in a given subject, as well as an application of thinking skills and sufficient linguistic knowledge to understand and present complex information orally and in writing. Therefore, in teaching vocabulary, teachers should pay attention to relating new words to the words students already know with similar structure or meaning by tapping into students' prior knowledge.

$\checkmark$ Providing multiple exposures

The fundamentally cyclical nature of language learning requires teachers and learners to regularly revisit language items in order to achieve a long-term memory. There is no exception to vocabulary acquisition. Vocabulary development also requires time and multiple exposures for the lexical items to become internalized. Teachers cannot expect students to remember a word or use it appropriately upon first exposure. Students need multiple exposures to achieve deeper processing of words and build a strong vocabulary foundation. Effective teachers present one use or function of a vocabulary word at a time, but review it many times over. They let students see and hear new words repeatedly, preferably in a variety of ways. They enhance students' understanding through repetition, demonstration, and drawing on multiple sources of meaning. They also engage students in creating examples and using the newly learned words for real-life purposes.

$\checkmark$ Providing a language-rich learning environment

Students should be immersed in a language-rich environment that provides varied language experiences. Exposure to new words, oral and written, in a variety of contexts across the curriculum, provides an important base for word learning.

$\checkmark$ Teaching vocabulary learning strategies, including word parts (roots, prefixes, and suffixes)

There is no way that students can learn all the words they need to know in their lifetime through instruction and memorization. They need to be cultivated into independent learners who are able to tackle an infinite number of new words on their own. It is therefore teachers' responsibility to help students grasp word-learning strategies. For example, it can greatly help expand students' vocabulary knowledge if they understand that many English words are formed with roots to which prefixes and suffixes are attached. It will also considerably benefit students if they are taught how to use dictionaries, and how to determine the meaning of unknown words in the textual context.

$\checkmark$ Developing word consciousness 
Helping students to develop an interest in and awareness of words should be an important part of vocabulary instruction. Teachers can start with guiding students to chunk the words with those they are frequently used, and advise students to go beyond the word to notice the phrase, clause, sentence, and even the paragraph in which the word is used to better understand the word. Students should be active in increasing their vocabulary and developing strategies for independent word learning. Other strategies teachers can use include (a) helping students recognize, understand, and use new words; (b) encouraging students to choose words they want to know about, manipulate words, and sort words; and (c) allowing plenty of opportunities for students to talk about words and negotiate meanings.

\section{CONCLUSION}

In today's classrooms characterized by diversity, all teachers have to prepare their curriculum and instruction that include ELLs, keep ELLs on grade level while developing their English proficiency. Language-minority students generally have lower academic performance than their native-English-speaking peers, and the reasons are multi-faceted. The vocabulary unique to each subject matter poses an unneglectable challenge as ELLs read and write academic texts. Not to say ELLs, even English-native-speaking students need time and effort to acquire the highly specialized academic vocabulary. Moreover, ELL students' challenges with academic vocabulary typically become greater in middle and high schools that have more structured and complex curricula with a higher demand on academic language.

This article examines how teachers can help ELL students develop academic vocabulary. After reading this article, teacher candidates should more acknowledge the importance of teaching academic vocabulary to ELLs, and better understand why sheltered instruction is indispensable for the learning of vocabulary and what Chomsky and Krashen's $1^{\text {st }}$ and $2^{\text {nd }}$ language acquisition theories imply to teachers concerning vocabulary teaching. Before discussing the various vocabulary development strategies, the article also illustrates the categories and the characteristics of academic vocabulary. Learning vocabulary is a cumulative process, and vocabulary must be deliberately taught, learned, and recycled. Undoubtedly, we have many excellent teachers who are passionate, devoted, and conscientious. Nevertheless, well-intentioned as they are, if without the knowledge of how to teach ELLs, they very likely will feel challenged, frustrated, and even defeated when working with ELLs who are regularly placed in their classrooms. It is hoped that teacher candidates will walk away with some guiding principles pertaining to vocabulary instruction and find these principles helpful in their classrooms with ELLs.

\section{REFERENCES}

[1] Beck, I. L., McKeown, M. G., \& Kucan, L. (2013). Bringing words to life: Robust vocabulary instruction. New York: The Guilford Press.

[2] Chomsky, N. (1957). Syntactic structures. The Hague: Mouton.

[3] Chomsky, N. (1965). Aspects of the theory of syntax. Cambridge, MA: MIT Press.

[4] Espinosa, L. M. (2008). Early literacy for English language learners. In A. DeBruin-Parecki (Ed.), Effective early literacy practice: Here's how, here's why (pp. 71-86). Baltimore, MD: Brookes Publishing.

[5] Freeman, D. E., \& Freeman, Y. S. (2011). Between worlds: Access to second language acquisition. Portsmouth, NH: Heinemann.

[6] Irwin, V., Zhang, J., Wang, X., Hein, S., Wang, K., Roberts, A., York, C., Barmer, A., Bullock Mann, F., Dilig, R., and Parker, S. (2021). Report on the Condition of Education 2021 (NCES 2021-144). U.S. Department of Education. Washington, DC: National Center for Education Statistics. Retrieved [date] from https://nces.ed.gov/pubsearch/pubsinfo. asp?pubid=2021144.

[7] Kena, G., Musu-Gillette, L., Robinson, J., Wang, X., Rathbun, A., Zhang, J., Wilkinson-Flicker, S., Barmer, A. \& Velez, E.D.V. (2015). The condition of education 2015. NCES 2015-144. Retrieved August 4, 2021 from https://www.learntechlib.org/p/158327/.

[8] Krashen, S. (1985). The input hypothesis: Issues and implications. London: Longman.

[9] Krashen, S. (2004a, Nov). Applying the Comprehension Hypothesis: Some Suggestions. Paper presented at the $13^{\text {th }}$ International Symposium and Book Fair on Language Teaching (English Teachers Association of the Republic of China), Taipei, Taiwan. Retrieved August 4, 2021 from http://www.sdkrashen.com/content/articles/eta_paper.pdf

[10] Krashen, S. (2004b, Jun). Free voluntary reading: New research, applications, and controversies. Paper presented at PAC5 (Pan-Asian Conference), Vladivostok, Russia. Retrieved August 4, 2021 from http://www.sdkrashen.com/content/articles/pac5.pdf

[11] Lawrence, J. F., White, C., \& Snow, C. E. (2011). Improving reading across subject areas with word generation. Washington, DC: Center for Research on Educational Achievement and Teaching of English Language Learners.

[12] Lewis, M. (1993). The lexical approach: The state of ELT and a way forward. Hove, England: Language Teaching Publications.

[13] Ovando, J., \& Combs, M. C. (2012). Bilingual and ESL classrooms: Teaching in multicultural contexts (5th ed.). McGraw-Hill Higher Education.

[14] Paton, A., \& Wilkins, M. (2009). Teaching adult ESOL: Principles and practice. Maidenhead, UK: Open University Press.

[15] Peregoy, S., \& Boyle, O. (2017). Reading and writing, and learning in ESL: A resource book for teaching K-12 English learners $\left(7^{\text {th }}\right.$ ed.). NJ: Pearson Education.

[16] Richard-Amato, P. A. (2010). Making it happen: From interactive to participatory language teaching--Evolving theory and practice $\left(4^{\text {th }}\right.$ ed. $)$. NY: Pearson Education.

[17] Sugarmann, J., \& Geary, C. (2018). English learners in Texas: Demographics, outcomes, and state accountability policies. Washington D.C.: Migration Policy Institute. 
[18] Wright, W. E. (2015). Foundations for teaching English Language Learners: Research, theory, policy and practice (2 ${ }^{\text {nd }}$ ed.). Philadelphia, PA: Caslon Publishing.

Liping Wei, Ed.D., is an Associate Professor of Curriculum and Instruction in the College of Education and Health Professions at the University of Houston-Victoria, TX, USA. Her research mainly draws on narrative inquiry and teachers' reflective practices to investigate the teaching experience of ELL teachers and the educational experience of language-minority students. 